\title{
Designing a National Initiative: Research and Budget Planning
}

\author{
Neville P. Clarke \\ Coalition for Advancement of Research on Agriculture, Food, and Environment, System Administration \\ Building, Room 308, Texas A\&M University, College Station, TX 77843-2129
}

The industry that supplies food and fiber to the citizens of the United States and many other countries, much like other industries, depends on a set of consistently available high-quality inputs, including natural resources that should be but are not always renewable in today's world. It targets its ultimate product to the consumer, whose concern for health, safety, and convenience has increased markedly in recent years. Like other industries, it must operate in a larger mileau where the effects of its actions must affect a broader set of environmental issues in an acceptable way.

The food and agriculture system, taken in the aggregate, is the largest industry in this country, with assets of more than a trillion dollars. It employs almost $20 \%$ of the U.S. work force. Last year, it provided $\$ 39$ billion in exports. It includes purchased inputs, production of raw products, processing and manufacturing, transportation, and marketing. Like any other industry today, the food and agriculture system must operate more effectively in a global market to survive in its present form. If this system can become more competitive in the international marketplace, it will be possible to substantially reduce burdensome farm support programs.

The availability of healthy, safe food at affordable prices is vital to every person; it is a matter of national priority in every country in the world. The food and agriculture industry is similar to the health care industry in terms of its relationship to a broader overriding agenda for human well being. There is growing awareness that the broad issues of food, health, and environment are interrelated, and that, in a more general societal sense, these and other such industries must reach beyond the strict economics at play and deal with the issues that affect human wellness in the broadest sense.

Thus, for the decade of the nineties, there has emerged a set of inextricably interrelated mandates for the U.S. food and agriculture system. They include 1) preserving and restoring the environment, 2) making prudent use of limited natural resources, 3) ensuring and enhancing the health and well being of the populace, and 4) increasing international competitiveness.

Recent advances in biological and engineering sciences provide unparalleled opportunities to address the mandates for the food and agriculture system. Beginning in the 1960s and increasing exponentially since than have been a series of breakthroughs in understanding the functions of biological systems and the genetic bases of these functions to the point where these new methods, coupled with the existing system of technology development and delivery, offer the prospect of revolutionary solutions to the complex prob-

Coordinator. lems facing the food and agriculture system today. Similarly, the advent of modern computer sciences and the ability to mathematically model complex interrelationships of production and processing systems is giving agriculture a new set of powerful tools to develop strategic and tactical management systems that minimize risk, conserve resources, and increase income.

Thus, the food and agriculture system of the United States finds itself at a unique intersection of need and opportunity: need for technological breakthroughs that will achieve the mandates of the 1990s; and opportunities in science and technology that offer the new promise of providing these breakthroughs. But what are the specifics at play? What are the dimensions of the problems to be solved, and how will science and technology contribute to the solutions? Finally, what needs to be done to make it happen?

Consumers are concerned about the safety and nutrional quality of their food, potentially harmful residues, microbial contamination, and nutritional effects of food on human health. Dietary imbalance or excess has been implicated as a risk factor in five of the 10 leading causes of death in the United States. Consumers effectively express their concerns politically and in the marketplace. The impact of these concerns is being felt by producers of food through a more constraining regulatory environment and increasing incentives or disincentives in conditions of purchase and pricing of products as they move through the food system from one part to another.

Modem methods in biotechnology are providing new tools for precise detection and identification of food contaminants. Methods to quantitatively measure chemical and microbial materials are rapidly advancing. The same science is being used to genetically engineer microorganisms to produce new food products with enhanced nutritive value and greater safety. Through use of new recombinant DNA methods, tools are being developed to accelerate the selection process in animal breeding to naturally produce meats and meat products with lower fat and cholesterol. In the longer run, these same methods will provide a means of precisely managing the genes that regulate deposition of fat in muscle, while maintaining the flavor and tenderness that is desired. New engineering technology in processing and preservation of food will reduce the possibility of microbial and chemical contamination. Genetically increasing the natural resistance of plants and animals to disease and pests will reduce the need for use of pesticides and antibiotics, getting to the original source of the problem.

One of the important mandates of the 1990s for the food and agriculture system is to make more effective use of this nation's natural resources and to reduce environmental contamination. Agriculture is considered to be the industry contributing most to non- 
point pollution in the United States today. The public as well as farmers and ranchers are calling for new technology and practices that address these concerns while maintaining an adequate food supply and an economically viable industry. Water quality is an example of the environmental concerns related to the food and agriculture system. Production practices are needed to reduce soil erosion and the use of harmful chemicals in production. Fertilizers as well as pesticides have been found in ground water and in streams across the United States, to greater or lesser degrees depending on soil type and other factors. Reducing the use of pesticides and chemical fertilizers through biotechnology will address not only the food safety issues described above but water quality issues as well. It is possible to reduce the use of highly toxic or persistent pesticides by as much as $50 \%$ in this decade. New research will help farmers meet the conservation requirements called for in the 1990 Farm Bill. Drought-tolerant plants, developed through adding biotechnology methods to plant breeding programs, offer promise in water conservation, as do continued improvements in efficient irrigation systems.

There is growing concern that the levels of $\mathrm{CO}_{2}$ and other gases in the atmosphere will produce meaningful climatic change. The impact of such change on the production of food and fiber and on broader ecosystems related to agriculture could be profound. It is necessary to begin now if the long-term studies needed to minimize the impact of such changes are to make an effective impact in the projected time frame of global change.

The food and agriculture system is a vital component of the U.S. industrial base; maintaining its international competitiveness is necessary if it is to continue to contribute to narrowing the trade deficit and provide a buffer to ensure adequate domestic supplies during adverse climatic conditions. Science and technology must supply U.S. farmers, foresters, land managers, and those in related supply and processing industries with the best and most competitive technology. There are several specific goals that illustrate what can be achieved: 1) reduce average production cost by as much as $15 \%$ in the 1990s, increasing farm income and international competitiveness; 2) increase the use of natural, capital, and human resources in sustainable enterprises to generate an additional economic activity of $\$ 20$ to 30 billion per year; and 3) expand the volume of U.S. exports, with special emphasis on value-added products, to create new jobs and improve the U.S. trade balance. The same general set of scientific tools must be brought to bear in making the major breakthroughs that will enhance the economic viability of the food and agriculture system.

A number of countries have a competitive advantage over the United States due to lower labor costs and more abundant natural resources. In other cases, our competitors are making major new investments in sophisticated technology that will give them a competitive edge. The United States must use new technology to offset the resource and labor advantages of its competitors in the international marketplace; it must keep pace with or excel in the technology race with more developed countries.

A critical concept that is apparent from the specific issues that have been addressed is the interdependency of science and technology for achieving separate goals and the mutual benefits across goals that result from their application to the issues at hand. Reducing pesticide use not only addresses food safety and environmental concerns, it reduces cost of production. Reducing environmental contaminants in agricultural operations first affects farming operations and those living in rural communities. Improving food safety and nutrition also creates new markets and better prices. Thus, the excitement lies in the fact that major new scientific opportunities can be applied to generate complimentary new technology to achieve multiple societal and economic goals.

It is also clear that the new science and technology opportunities at hand cannot displace the existing nationwide network of federal and state activity that continues to be most effective in generating site-specific and applied knowledge and assuring that this knowledge is made available as quickly as possible to those who will use it.

Given the broad potential for use of new opportunities in science and engineering to meet the mandates of the 1990s for the food and agriculture system, some assessment of the status of these new capabilities provides useful perspective. Many but not all of the fundamental methods have been developed in plant, animal, and microbial biology to manipulate genetic material and define functional implications of various genetic codes. Early progress in microbial systems, used as factories to produce biologically active materials such as human insulin, has provided commercial application of recombinant DNA technology. The major initiative in mapping the human genome represents a long-term investment in human health that is generating a parallel set of efforts at mapping plant and animal genomes. Major new progress has been made in detection of and diagnostic technology in animal and human disease. Efforts to achieve disease or insect resistance in plants are nearing practical applications, as is development of plant products with more desirable flavor and longer shelf life than those now available. Genetic engineering techniques are being used today to enhance and substantially accelerate traditional plant and animal breeding studies. Universities have redirected existing resources into this new science. Federal and state governments have provided limited new resources to these opportunities. Industry has invested substantially but is understandably involved in near-term research and development with obvious implications for economically important product development. It is fair to say that the research and development community has come along far enough to clearly show that science can be effectively directed to pressing problems in the food and agriculture system, but ii is also clear that there has been a major under-investment relative to the opportunity at hand. What is needed at this point is a major investment of new funds in the science and engineering research and education systems that is relevant to the food and agriculture system.

Recent studies have estimated an annual rate of return from all research at $28 \%$ per year. The estimated return on applied agricultural research was $150 \%$ to $180 \%$ per year, and from basic agricultural research was $116 \%$ to $180 \%$. Preliminary forecast studies of future benefits suggest a continuing opportunity of similar proportions. The size of the measured rates of return on previous investments clearly shows a major under-investment in agricultural research. The payoff should be even greater when new capabilities in biology and engineering are combined with on-going R\&D.

Federal funding for agriculture tends to be crisis-oriented, as exemplified by recent drought relief funds of more than $\$ 3.9$ billion and the farm credit system bailouts of more than $\$ 2.5$ billion. Longerterm federal funding for agricultural research has been virtually stagnant for the last two decades, when considered in terms of constant dollars. Figure 1 shows the relative growth of funding for agriculture as compared to other parts of the federal science community; it falls dead last.

The National Academy of Sciences/National Research Council's Board on Agriculture produced a watershed report that deals with these needs. It is entitled, "Investing in Research: A Proposal to Strengthen the Agricultural, Food and Environmental System" (Oct.

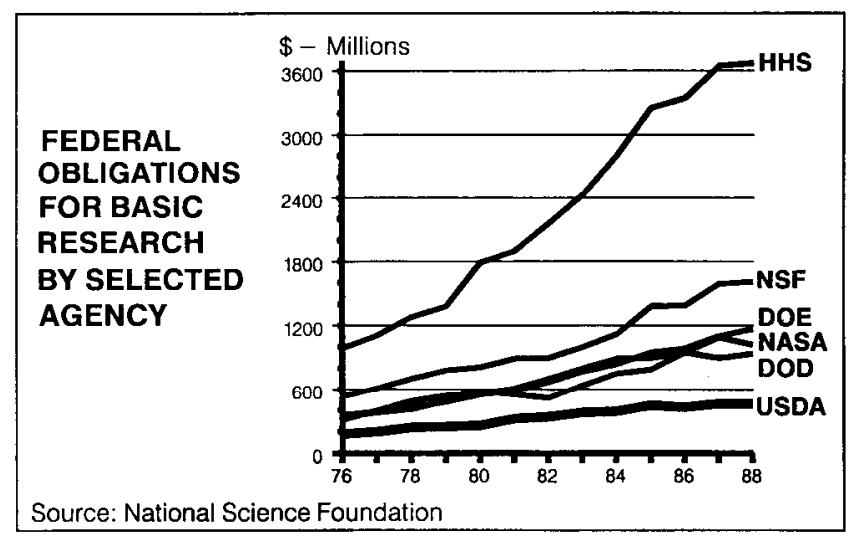

Fig. 1. Funding for basic research in selected U.S. agencies over 12 years (HHS, Health and Human Services; NSF, National Science Foundation; DOE, Dept. of Energy; NASA, National Aeronautic and Space Agency; DOD, Dept. of Defense; USDA, U.S. Dept. of Agriculture). 
1989). The study undertakes a thorough assessment of need, opportunity, funding options, and relations between new and existing programs. It represents a broad consensus of industry, conservationists, environmentalists, consumers, government, and academia. The report calls for a major new initiative in the U.S. Dept. of Agriculture (USDA) to increase competitive grant funding by adding $\$ 500$ million per year of new funds to existing $R \& D$ programs in the department. It addresses the needs and opportunities that have been described above.

The USDA has taken the National Academy's report as a major guideline in undertaking a National Initiative for Research on Agriculture, Food and Environment. The Initiative was funded at $\$ 73$ million in fiscal year (FY) 1991 (representing about \$30 million of new funds added to the existing USDA Competitive Grants Program). The President's budget for N 1992 recommends the initiative be funded at $\$ 125$ million per year. The 1990 Farm Bill authorizes full funding of the Initiative at $\$ 500$ million per year. The Administration has also proposed to increase funding for the initiative in future years to the proposed level of $\$ 500$ million per year. Further, the President's budget contains \$25 million for a competitive facilities grant program that is linked to the National Research Initiative. With the initiative fully funded at $\$ 500$ million per year, the facilities program would grow to $\$ 100$ million per year. The future year commitment to agricultural research is unprecedented and demonstrates a truly outstanding commitment of the Administration to USDA's Science and Education programs.

In addition to the National Academy's report, another significant input to the USDA's National Research Initiative is the strategic plan for research in the State Agricultural Experiment Stations. This plan draws on recommendations form agricultural industries, environmental groups, consumer groups, policy makers in government, professional and scientific societies, other federal research and extension agencies, and input from the four regional associations of directors of agricultural experiment stations. More than 600 individual recommendations for needed research were received. The plan was developed by the Experiment Station Committee on Organization and Policy (ESCOP) and the Cooperative State Research Service (CSRS). ESCOP is affiliated with the National Association of State Universities and Land Grant Colleges (NASULGC).

The National Academy study developed the case statement for the National Initiative and prescribed the general areas of science that should be included, as well as the structure of the granting mechanism. The ESCOP-CSRS strategic plan, viewed as a statefederal plan, provided the detailed inputs that gave specific programatic substance to the Academy proposal. The resulting USDA program plan, published in Jan. 1990 and revised in Feb. 1991, represents, therefore, a broad consensus of users and performers of research about the agenda for the 1990s. The combined input assures that the most critical areas are addressed and that grants will be oriented to cutting edge science.
The National Research Initiative calls for new funding in six broad areas of science that address the critical issues and opportunities previously identified. The six areas are: 1) natural resources and environment, 2) nutrition, food quality, and health, 3) new products, processes, and adding value to raw products, 4) markets, trade, and policy, 5) animal systems, and 6) plant systems.

All qualified academic institutions, federal laboratories, and notfor-profit organizations would be eligible to receive competitive grant funds. Four major types of grants would be awarded: Basic Science Research, 1) Individual Investigator (40\%), 2) Multidisciplinary Investigator (30\%); and Mission-linked Research, 3) Mission linked (Applied) (20\%), 4) Strengthening Grants (10\%).

The initiative will address major shortcomings in the existing USDA competitive grants program by providing funds to allow for size and duration of grants to be competitive with other federal granting agencies and to increase the funding rate for quality proposals.

Adding \$500 million per year to USDA-sponsored research would increase the total funding by $\approx 30 \%$. It would bring the percentage of funds awarded competively up from $<5 \%$ to $\approx 25 \%$, making the USDA program comparable to that of the National Institutes of Health in that respect.

The Coalition for Advancement of Research on Agriculture, Food, and Environment (CARAFE) has been formed to link institutional and industrial advocates for the Initiative. CARAFE now has $\approx 130$ such members, more than 70 of which represent commitments by the presidents and chancellors of both land-grant and nonland-grant universities. All elements of NASULGC are active supporters of the Initiative as are the Assn. of American Universities, The American Assn. of State Colleges and Universities, and The American Assn. of State Colleges of Agriculture and Renewable Resources. Other members come from scientific and professional organizations (including ASHS), national commodity and farm organizations, and umbrella organizations representing manufacturing and processing industries. This represents the broadest consensus and support for an initiative in research for food and agriculture that has been mustered in modern times.

A compelling case has been made for taking up the National Research Initiative, even in the face of the deficit. The case would seem to be solidly made that the Initiative is not a cost but an investment with a very high rate of expected return. With urgent new needs and numerous scientific opportunities, it is time to make such a significant investment in research for the food and agriculture system; a proactive investment in the future. It is time to develop the technology that will allow for avoiding or reducing risk, rather than reacting to crisis. It is time to make an investment that addresses broad issues that are crucial not just to a major U.S. industry but to every citizen whose well-being and quality of life will be enhanced by the results. 